\title{
PENGELOLAAN PEKARANGAN UNTUK PENCEGAHAN BANJIR DI KELURAHAN MATANI 3
}

\author{
Fabiola B. Saroinsong ${ }^{1)}$, Josephus I. Kalangi ${ }^{2)}$ \\ Fakultas Pertanian Universitas Sam Ratulangi \\ Email: fabiolasaroinsong@ymail.com
}

\begin{abstract}
ABSTRAK
Upaya pengendalian banjir yang mencakup semua metode yang digunakan untuk mengurangi atau mencegah efek merugikan dari air banjir perlu dilakukan untuk menjamin keberhasilan jangka panjang. Pembekalan dan pengkayaan ilmu dan teknologi kepada masyarakat umum berkaitan pengelolaan air hujan, pengelolaan tutupan lahan, pembuatan biopori, dan penanaman vegetasi diharapkan dapat berkontribusi pada upaya pencegahan banjir. Tujuan kegiatan ini adalah melakukan diseminasi Iptek dalam bentuk penyuluhan tentang teknik pengelolaan pekarangan untuk pencegahan banjir di area pemukiman dan sekitarnya. Metode pelaksanaan kegiatan yaitu penyuluhan/penyadaran. Mitra Kegiatan IbM ini kelompok masyarakat umum dan PKK Kelurahan Matani 3. Lokasi kegiatan pengabdian Kelurahan Matani 3 Kota Tomohon, Sulawesi Utara. Metode pelaksanaan kegiatan yaitu penyuluhan/penyadaran, dengan waktu efektif pelaksanaan kegiatan yaitu enam (6) bulan. Kedua mitra IbM menyambut baik pelaksanaan pengabdian ini, bahkan mereka menunjukkan sikap antusias dan meminta agar dilakukan kegiatan pengabdian lanjutan untuk turut berkontribusi dalam pelestarian lingkungan hidup Tomohon, lebih khusus lagi berkaitan konservasi tanah dan air. Lurah juga mengusulkan untuk melakukan kunjungan ke rumah-rumah warga untuk pendampingan dalam melaksanakan tindakan praktis konservasi lingkungan. Hal ini dinilai sangat baik oleh Tim Pelaksana IbM maupun mitra karena lebih menjamin bahwa pelaksanaan IbM tidak hanya pada tingkatan teoristis tapi juga aplikasinya.
\end{abstract}

Keywords: konservasi, lubang resapan biopori, pengendalian banjir, pengelolaan pekarangan 


\section{PENDAHULUAN}

Banjir adalah kondisi di mana air permukaan dalam jumlah berlebih sehingga merendam bagian daratan, dan terjadi akibat dari 2 faktor, yaitu faktor alam (intensitas curah hujan yang tinggi) dan faktor manusia (mengalihfungsikan dan merubah permukaan tanah daerah resapan, memperbesar luasan daerah terbangun, mengganggu fungsi drainase dengan membuang sampah, dan lain-lain) (Soemarwoto, 1997; Keraf, 2004; Bennett, Peterson, and Gordon, 2009; Reyers et al, 2009). Banjir menimbulkan banyak masalah bahkan ancaman pada kenyamanan, kesehatan, dan keselamatan manusia serta keberlanjutan lingkungan itu sendiri ( Seumahu, Nuryanti, dan Rustaman, 1981; Widada dan Kobayashi, 2004; Keraf, 2004; Manik, 2007).

Masyarakat umumnya berpikir bahwa banjir hanya akan terjadi pada daerah dataran rendah, dan atau daerah dekat badan air seperti sungai, danau, dan laut. Kenyataannya, banjir dapat saja terjadi di dataran tinggi misalnya peristiwa banjir 19-20 Februari 2017 di beberapa daerah dataran tinggi termasuk Kelurahan Matani 3, Kota Tomohon (Gambar 1, 2, dan 3). Genangan air di jalan dan pada rumah-rumah penduduk yang terkena dampak beragam, tapi ada yang bahkan sampai sekitar $120 \mathrm{~cm}$.

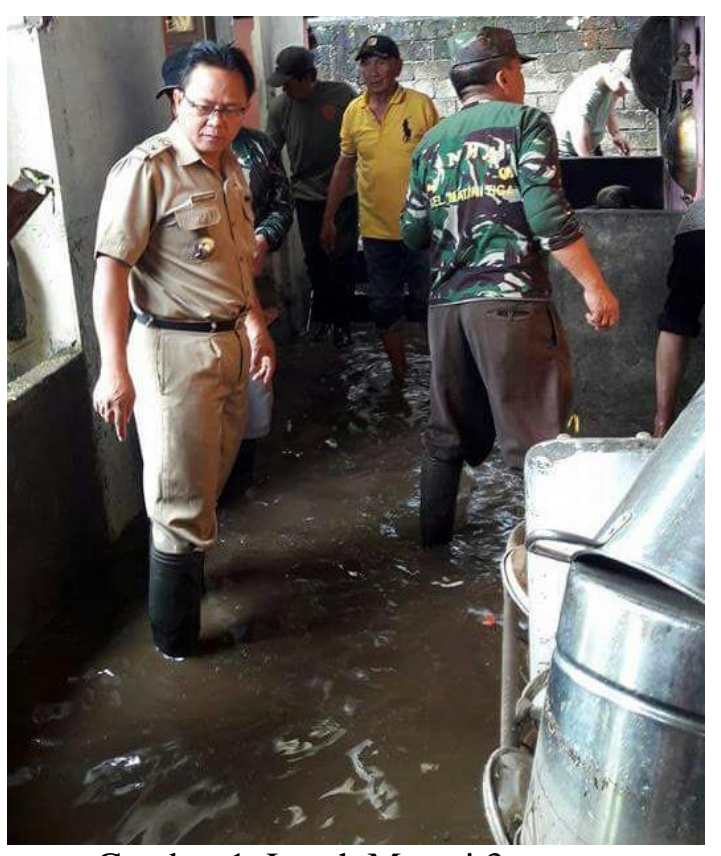

Gambar 1. Lurah Matani 3 yang Mengunjungi Warga yang Panik Karena

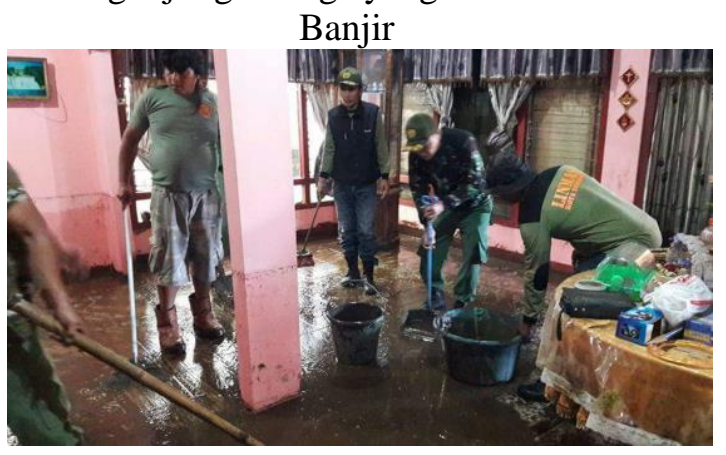

Gambar 2. Endapan Lumpur Setelah Banjir Surut di Rumah Warga

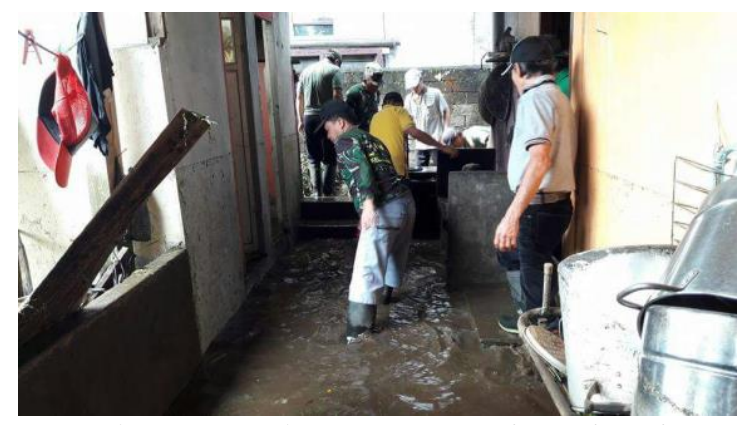

Gambar 3. Tanda Genangan Air Setinggi

120cm di Rumah Salah Satu Warga 
Secara khusus di lingkungan mitra, permasalahan yang bisa diamati pada survey awal adalah masih rendahnya pemahaman masyarakat tentang lingkungan, yang berimplikasi pada perilaku membuang sampah sembarangan, tidak memelihara saluran drainase, kurang menanam dan memelihara pohon dan tanaman lainnya, serta trend menutupi halaman yang tersisa dengan perkerasan.

Tim Pengusul dan Mitra menyepakati bahwa inti persoalan yang akan diselesaikan selama pelaksanaan program IbM ini adalah bagaimana meningkatkan pengetahuan masyarakat tentang lingkungan dan apresiasi terhadap lingkungan, dan meningkatkan kemampuan masyarakat untuk melakukan pengelolaan pekarangan dengan tindakantindakan praktis konservasi sehingga diharapkan akan diaplikasikan dalam kehidupan mereka sehari-hari. Demo tindakan-tindakan praktis konservasi lingkungan di pekarangan rumah serta pelibatan peserta penyuluhan perlu dilakukan sehingga pendidikan konservasi tidak hanya pada tingkatan teoristis tapi diwujudkan dalam aksi nyata (Bennett, Peterson, and Gordon, 2009; de Groot, et al., 2009; Hasbullah, 2009; Bryan, Raymond, Crossman, and MacDonald, 2010; Ahmadi, Sadeghi, and Eskandarinezhad, 2016). Tujuan kegiatan ini adalah melakukan diseminasi Iptek dalam bentuk penyuluhan tentang teknik pengelolaan pekarangan untuk pencegahan banjir di area pemukiman dan sekitarnya.

Solusi yang ditawarkan untuk menyelesaikan permasalahan mitra adalah:

1. Meningkatkan pengetahuan dan pemahaman kelompok masyarakat mengenai cara pengelolaan pekarangan sehingga selain produktif dan estetis, juga efektif dalam pencegahan dan penekanan resiko banjir.

2. Meningkatkan ketrampilan kelompok masyarakat berkaitan beberapa aplikasi praktis teknik pengelolaan pekarangan yang memungkinkan untuk diterapkan di lingkungannya sendiri.

\section{METODE PELAKSANAAN}

Kegiatan IbM ini secara keseluruhan berlangsung selama 6 (enam) bulan. Lokasi kegiatan adalah Kelurahan Matani 3 Kota Tomohon Provinsi Sulawesi Utara (Gambar 4).

Metode pendekatan yang diterapkan dalam kegiatan IbM ini adalah Tahapan Pendidikan Konservasi. Empat (4) tahapan pendidikan konservasi yang dilaksanakan seperti yang diusulkan oleh Megantara dan Noviar (2001) adalah sebagai berikut:

- menambah pengetahuan tentang lingkungan

- menumbuhkan apresiasi terhadap lingkungan

- menstimulasi kesadaran dan motivasi untuk melakukan konservasi lingkungan 
- melatih aplikasi praktis konservasi dan menstimulasi tindakan konservasi mandiri.

Prosedur kerja kegiatan pengabdian

kepada masyarakat adalah sebagai berikut.

1) Analisis situasi dan permasalahan serta penetapan program.

2) Penentuan topik dan kedalaman materi penyuluhan serta pelatihan.

3) Pelaksanaan kegiatan transfer pengetahuan melalui penyampaian materi dan tanya jawab.

4) Pembuatan demo dan pelibatan langsung kelompok masyarakat berkaitan teknik-teknik pengelolaan pekarangan.

5) Evaluasi.

6) Pembuatan laporan dan publikasi.

Sumber: Bappeda Kota Tomohon

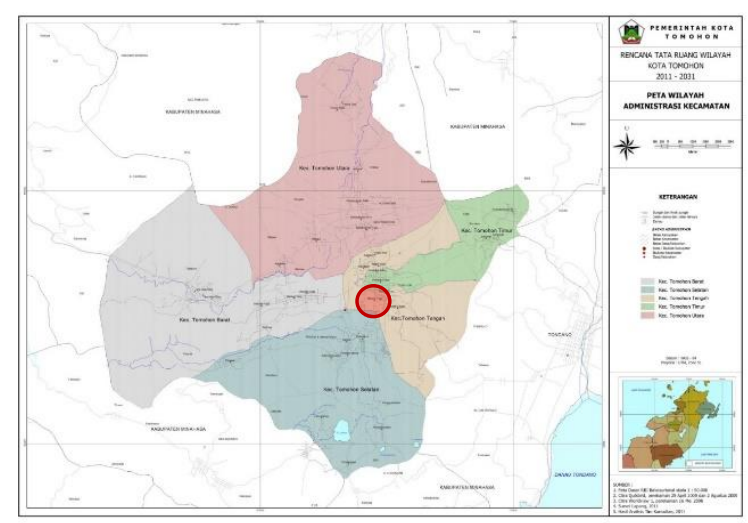

Gambar 4. Peta Lokasi Kegiatan IbM

Mekanisme dan koordinasi pelaksanaan kegiatan ini, secara internal berdasarkan pada asas-asas manajemen yang bertumpu pada prinsip pendelegasian wewenang dan tanggung jawab kepada segenap tenaga yang terlibat. Koordinasi dan komunikasi yang baik dari Tim Pengusul dan Mitra akan dijaga dengan baik untuk kelancaran kerja sama.

\section{PEMBAHASAN}

Banjir pada daerah dataran tinggi diakibatkan beberapa faktor seperti drainase yang buruk karena pengaturan aliran permukaan yang tidak baik, atau tertutupnya saluran air oleh sampah, atau terbendungnya sungai karena longsoran tanah, juga bisa disebabkan oleh erosi hebat diikuti sedimentasi sungai dan danau. Penyebab lainnya adalah perubahan tutupan lahan dengan penebangan pohon dan atau pembangunan di kawasan yang miring yang membuat fungsi penahan air sangat berkurang, penutupan tanah dengan material yang tidak bisa atau kurang meresapkan air di kawasan pemukiman dan bisnis sehingga peresapan air jauh lebih rendah. Hal lain adalah diubahnya daerah-daerah resapan air menjadi peruntukan yang lain misalnya pertanian atau pemukiman (Manik, 2007; Kardan, 2015).

Pencegahan banjir harus dilakukan secara komprehensif dan dalam skala besar (Widada, M. S., Kobayashi H. 2003; Prihandanni, R. 2004; Diaz, 2007; Isrol, 2008; de Groot, 2009; Wascher and Haines-Young, 2009; Bryan, Raymond, Crossman, and MacDonald, 2010; Sasaoka and Laumonier, 2012). Di antaranya mencakup pembekalan dan pengkayaan ilmu dan teknologi kepada masyarakat luas mengenai pengelolaan 
air hujan dan drainase, pengelolaan tutupan lahan, penanaman vegetasi untuk pencegahan banjir dan lain-lain, serta peningkatan ketrampilan tindakan-tindakan praktis konservasi tanah dan air (Gambar 5).
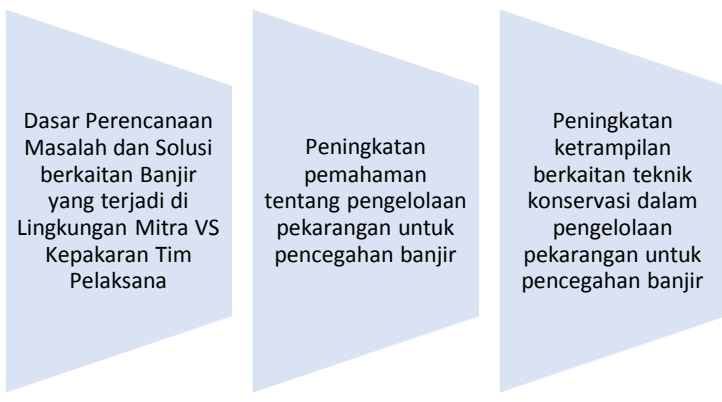

Gambar 5. Gambaran Iptek yang Ditransfer kepada Kedua Mitra

Peningkatan lahan terbangun di Kota Tomohon dan sekitarnya mengakibatkan banyaknya konversi tutupan lahan, yang mana permukaan kedap air semakin luas. Implikasinya adalah berkurangnya infiltrasi, menurunnya pengisian air tanah, dan meningkatnya limpasan permukaan (Reyers et al, 2009; Maria dan Lestiana, 2014). Sebagai salah satu langkah untuk mempertahankan fungsi hidrologis kawasan dan menekan potensi banjir, maka 2 (dua) metode yang dapat dilakukan masyarakat adalah metode rekayasa teknologi dan metode vegetatif. Metode rekayasa teknologi dapat dilakukan dengan pembuatan lubang resapan baik lubang resapan biopori maupun sumur resapan. Yang dapat dilakukan dengan lebih mudah adalah lubang resapan biopori. Metode vegetatif adalah dengan melakukan penanaman tumbuhan.

Penanaman tanaman penutup tanah yang berperan (1) menahan atau mengurangi daya perusak butir-butir hujan yang jatuh dan aliran air di atas permukaan tanah, (2) menambah bahan organik tanah melalui batang, ranting dan daun mati yang jatuh, dan (3) melakukan transpirasi, yang menghindari genangan, beberapa jenis dapat menambah penghasilan atau untuk kebutuhan estetika. Tanaman menyebabkan berkurangnya kekuatan dispersi air hujan, mengurangi jumlah serta kecepatan aliran permukaan dan memperbesar infiltrasi air ke dalam tanah (Arsyad, 2006; Reyers, 2009). Mengubah sebagian penutupan lahan dengan perkerasan ke tanaman dapat berkontribusi dalam pengelolaan banjir. Beberapa pilihan tanaman penutup tanah adalah sebagai berikut.

1. Jenis rumput-rumputan, dan tanaman yang merambat dan menjalar di atas permukaan tanah.

a. Ditanam rapat, misalnya: Calopogonium muconoides Desv, Centrosema pubescens Benth, Mimosa invisa.

b. Ditanam dalam barisan, misalnya: Eupatorium triplinerve Vahl, Salvia occidentalis, Ageratum mexicanum Sims.

c. Ditanam sebagai penguat teras dan saluran air, antara lain: Althenanthera amoena 
Voss, Pennisetum purpureum, Oxalis corymbosa DC.

2. Jenis perdu

a. Sebagai tanaman selingan di Antara baris tanaan pokok, seperti: Eupatorium pallessens DC.

b. Sebagai tanaman pagar, misalnya: Crotalaria anagyroides HBK, Lantana camara L, Gliricidia maculate.

c. Sebagai sumber pupuk hijau dan mulsa, atau untuk penghutanan dan perlindungan dinding jurang, misalnya: Cordyline fruticosa, Leucaena glauca (L) Benth

3. Jenis pohon

Ditanam sebagai tanaman utama dalam area, atau ebagai pelindung di bagian area yang berkelerengan tinggi. Contohnya antara lain: Albizi falcate, Erythrna sp, Eucalypthus saligna, Bambusa bambos, Acacia mangium. Dalam kegiatan IbM ini disediakan 230 bibit beberapa jenis pohon yaitu mahoni, kayu besi, jabon, mangga, rambutan, dan durian.

Biopori adalah lubang-lubang kecil atau poripori di dalam tanah yang terbentuk akibat berbagai akitifitas organisme di dalamnya, seperti cacing, , perakaran tanaman, rayap dan fauna tanah laiinya. Pori-pori yang ada dapat menigkatkan kemampuan tanah menahan air dengan cara menyirkulasikan air dan oksigen ke dalam tanah. Jadi, semakin banyak biopori di dalam tanah, semakin sehat tanah tersebut. Di daerah yang masih alami, mekanisme pembentukan biopori terjadi dengan sendirinya. Dengan adanya perubahan struktur di atas dan di dalam tanah akibat pembangunan/ pengolahan tanah yang dilakukan manusia seperti pertanian, deforestasi dan perumahan, mekanisme alamiah pembentukan biopori menjadi tidak berjalan. Untuk mengatasi permasalahan ini, Kamir R. Brata, seorang peneliti dari Institut Pertanian Bogor (IPB), mengembangkan sebuah cara untuk mendorong terbentuknya biopori melalui Lubang Resapan Biopori (LRB). Lubang resapan biopori adalah teknologi tepat guna dan ramah lingkungan untuk mengatasi banjir dengan cara meningkatkan daya resapan air, mengubah sampah organik menjadi kompos dan mengurangi emisi gas rumah kaca (CO2 dan metan), dan memanfaatkan peran aktivitas fauna tanah dan akar tanaman, dan mengatasi masalah yang ditimbulkan oleh genangan air seperti penyakit demam berdarah dan malaria. Lubang resapan biopori adalah suatu metode resapan air yang ditujukan untuk mengatasi banjir dengan cara meningkatkan daya resap air pada tanah (Tim Biopori IPB, 2007a; Tim Biopori IPB, 2007b; Tim Biopori IPB, 2007c; Brata dan Nelistya, 2008; Herf, J. 2008; Isrol, 2008; Brata, 2009; Prana, 2009; Fadhilah, 2011). Manfaat lubang resapan biopori adalah:

- Meningkatkan daya resapan air.

- Mengurangi genangan air yang menimbulkan penyakit. 
- Mencegah terjadinya erosi tanah dan bencana tanah longsor.

- Mengurangi resiko banjir di musim hujan. Sampah sudah menjadi permasalahan lingkungan. Masyarakat juga dibekali dengan pengetahuan 3R (reduce, reuse and recycle) dan teknik sederhana mengolah sampah rumah tangga. Selain itu masyarakat dibangkitkan motivasi dan peran sertanya untuk mengelola sampah.

Mitra IbM menyambut baik pelaksanaan pengabdian ini, bahkan kedua mitra menunjukkan sikap antusias dan meminta agar dilakukan kegiatan pengabdian lanjutan untuk turut berkontribusi dalam pelestarian lingkungan hidup Tomohon, lebih khusus lagi berkaitan konservasi tanah dan air. Lurah juga mengusulkan untuk melakukan kunjungan ke rumah-rumah warga untuk pendampingan dalam melaksanakan tindakan praktis konservasi lingkungan. Hal ini dinilai sangat baik oleh Tim Pelaksana IbM maupun mitra karena lebih menjamin bahwa pelaksanaan IbM tidak hanya pada tingkatan teoristis tapi juga aplikasinya.

\section{PENUTUP}

Sejak survey pelaksanaan IbM sampai pelaksanaannya, kedua mitra menunjukkan minat dan berperan aktif. Mitra meminta agar program IbM dilakukan lagi khususnya lebih menekankan pada pelatihan dan pendampingan aplikasi konservasi di lingkungan pemukiman. Evaluasi dan perbaikan program diperlukan agar semakin bermanfaat bagi masyarakat luas.

\section{REFERENSI}

Ahmadi F., Sadeghi A. R. , and Eskandarinezhad A. R. 2016. Ecological Quality Improvement of Urban Landscapes with Emphasis on Sustainable Development Principles Case Study: River of Darabad Valley, Tehran, Iran. European Journal of Sustainable Development 5(3): 91-102.

Arsyad, S. 2006. Konservasi Tanah dan Air. Bogor, IPB Press.

Bennett, E.M., Peterson, G.D. \& Gordon, L.J. (2009) Understanding relationships among multiple ecosystem services. Ecology Letters, 12, 1394-1404.

Brata, K. R., Nelistya, A. 2008. Lubang Resapan Biopori. Bogor.

Brata, K. R. 2009. Lubang Resapan Biopori untuk Mitigasi Banjir, Kekeringan dan Perbaikan. Prosiding Seminar Lubang Resapan Biopori (LBR) dapat Mengurangi Bahaya Banjir. Gedung BPPT, Jakarta.

Bryan, B.A., Raymond, C.M., Crossman, N.D. \& MacDonald, D.H. 2010. Targeting the management of ecosystem services based on social values: where, what, and how? Landscape and Urban Planning, 97, 111122.

de Groot, R.S., Alkemade, R., Braat, L., Hein, L. \& Willemen, L. 2009. Challenges in integrating the concept of ecosystem services and values in landscape planning, management and decisionmaking. Ecological Complexity, 7, 260-272

Diaz, S., Lavorel, S., De Bello, F., Que' tier, F., Grigulis, K. \& Robson, T.M. (2007) Incorporating plant functional diversity effects in ecosystem service assessments. Proceedings of the National Academy of Sciences, 104, 20684-20689. 
Egoh, B., Reyers, B., Rouget, M., Bode, M. and Richardson, D.M. (2009) Spatial congruence between biodiversity and ecosystem services in South Africa. Biological Conservation, 142, 553-562.

Hasbullah, H. 2008. Pendidikan Konservasi untuk Orang Dewasa. Tropika 13.

Isrol, 2008. Pengomposan Limbah Padat Organik. Balai Penelitian Bioteknologi Perkebunan Indonesia. Bogor.

Kardan, O. 2015. Neighborhood Greenspace and Health in a Large Urban Center. International Journal of Environmental Health Research 15: 319-337.

Keraf, S. 2004. Bencana dan Krisis Lingkungan Global. Materi TOT PKLH Dikdasmen di Sawangan Bogor.

Manik, K. E. S. 2007. Pengelolaan Lingkungan Hidup. Penerbit Djambatan, Jakarta.

Maria, R. dan Lestiana, H. 2014. Pengaruh Penggunaan Lahan terhadap Fungsi Konservasi Air Tanah d Sub DAS Cikapundung. Riset Geologi dan Pertambangan Vol. 24(2): 77-89.

Megantara, Noviar, E. 2001. Pengelolaan Lingkungan Hidup. Modul Kerjasama Bappeda Provinsi Jabar dengan Unpad.

Prihandanni, R. 2004. Manajemen Sampah, Daur Ulang Sampah Menjadi Pupuk Organik. Jakarta.

Reyers, B.,O'Farrell, P.J., Cowling,R.M., Egoh, B.N.,Maitre, D.C.L. and Vlok, J.H.J. 2009 Ecosystem services, land-cover change, and stakeholders: finding a sustainable foothold for a semiarid biodiversity hotspot. Ecology and Society, $14, \quad 38$ [http://www.ecologyandsociety.org/vol14/i ss1/art38].

Sasaoka, M and Laumonier, Y. 2012. Suitability of Local Resource Management Practices Based on Supernatural Enforcement Mechanisms in the Local Social-cultural
Context. Ecology and Society 17(4): 6 http://www.ecologyandsociety.org/ vol17/iss4/art6/

Seumahu, J.G., Nuryanti, Y., Rustaman. 1981. Kelestarian Alam. Jakarta: Departemen Pendidikan dan Kebudayaan.

Setyowati, D. L., Sunarko, Rudatin, Sedyawaati S. M. R. 2014. Pendidikan Lingkungan Hidup. Universitas Negeri Semarang

Soemarwoto, O. 1997. Ekologi, Lingkungan Hidup dan Pembangunan. Jakarta: Penerbit Jambatan

Sutrisno, D. (Ed). 2005. Pendidikan Lingkungan Hidup. Buku Pegangan Guru SD Kerjasama Bappedal Prov. Jateng dengan FMIPA UNNES.

Tim Biopori IPB. 2007. Biopori Teknologi Tepat Guna Ramah Lingkungan - Pengantar. http://biopori.com diakses 27 Februari 2017.

Tim Biopori IPB. 2007b. Biopori Teknologi Tepat Guna Ramah Lingkungan - Keunggulan dan Manfaat. http://biopori.com diakses 1 Maret 2017.

Tim Biopori IPB. 2007c. Biopori Teknologi Tepat Guna Ramah Lingkungan - Lokasi Pembuatan. http://biopori.com diakses 1 Maret 2017.

Wascher, D. \& Haines-Young, R. 2009. Assessing landscape functions with broad-scale environmental data: insights gained from a prototype development for Europe. EnvironmentalManagement, 44, 10991120.

Widada, M. S., Kobayashi H. 2003. Sekilas tentang Konservasi Sumberdaya Alam Hayati dan Ekosistemnya. Biodiversity Conservation Project. Bogor 